\title{
Simulating an induction motor multi-operating point speed control using PI controller with neural network
}

\author{
Mazin Abdulelah Alawan ${ }^{1}$, Ahmed Najim Nimir Al-Subeeh ${ }^{2}$, Oday Jasim Mohammed Al-Furaiji ${ }^{3}$ \\ ${ }^{1,2,3}$ Shatt Alarab College University, Iraq
}

\section{Article Info}

Received, 2019

\begin{abstract}
The Induction Motors (IM) speed widely influenced due to various motor loading conditions. When the load is apply the motor speed is reduce from the reference speed. This work present Matlab simulation of a Proportional Integral (PI) controller incorporating with Neural Network for IM speed controls. The motor speed response profile under this control is improved and still constant at the point of load applied. Also this controller stilled operates efficiently at wide range of operating frequency when compared with traditional PI controller.
\end{abstract}

\section{Corresponding Author:}

Mazin Abdulelah Alawan

Shatt Alarab College University, Iraq.

Email: drmazinalwan@gmail.com,

\section{Introduction}

Generally, induction motor is considered as a common electric motor which is used in most applications. Obviously, when the induction motor is connected to the appropriate ac voltage source, the flux will be generated in the stator coil as a result of the current flow in this coil. The rotor winding is short-circuits. When the stator flux cuts the rotor coils, the current will start to flow in the rotor coil. Therefore, another flux will be created in the rotor windings. Now there will be two flows, one is the stator flux and another is the rotor flux and the rotor flux will lag back to the stator flux. Therefore, the rotor will rotate due to owning torque. The rotor speed can be influenced by changing the input supply frequency and can be used to control it [1-3].

One of the common techniques used in closed loop speed control of motor induction is the Voltage/Frequency $(\mathrm{V} / \mathrm{F})$. Also the IM motor torque is directly effects by the V/F ratio. If the voltage and frequency are changed with ratio constant, lead the torque produced by induction motor will stay constant for all the speed range [1]. The aim of this paper is to combine neural network with PI controller in order to control the speed of IM motor for wide range of operating points.

\section{Simulation of induction motor:}

A dynamic model of the machine subjected to a control must be known in order to understand and design the vector controlled drives. The Direct and Quadrate mathematical model of three-phase induction motor expressed in stator reference frame is given by [4-6]:

$$
\left[\begin{array}{c}
v_{q s} \\
v_{d s} \\
0 \\
0
\end{array}\right]=\left[\begin{array}{cccc}
R_{s}+L_{s} p & 0 & L_{m} p & 0 \\
0 & R_{s}+L_{s} p & 0 & L_{m} p \\
L_{m} p & -\omega_{r} L_{m} & R_{r}+L_{r} p & -\omega_{r} L_{r} \\
\omega_{r} L_{m} & L_{m} p & \omega_{r} L_{r} & R_{r}+L_{r} p
\end{array}\right]\left[\begin{array}{c}
i_{q s} \\
i_{d s} \\
i_{q r} \\
i_{d r}
\end{array}\right]
$$


Where $\omega_{r}=\frac{d \theta}{d t}$ and $p=\frac{d}{d t}$

When assuming the flux linkages as variables the dynamic equations of the motor can be represented in any reference frame. The d-q components of flux linkages for the motor stator and rotor are:

$$
\begin{aligned}
& \lambda_{q s}=L_{s} i_{q s}+L_{m} i_{q r} \\
& \lambda_{d s}=L_{s} i_{d s}+L_{m} i_{d r} \\
& \lambda_{q r}=L_{r} i_{q r}+L_{m} i_{q s} \\
& \lambda_{d r}=L_{r} i_{d r}+L_{m} i_{d s} \\
& \text { From (1) - (5) we get: } \\
& v_{d s}=R_{s} i_{d s}+\frac{d \lambda_{d s}}{d t} \\
& v_{q s}=R_{s} i_{q s}+\frac{d \lambda_{q s}}{d t} \\
& 0=R_{r} i_{d r}+\omega_{r} \lambda_{q r}+\frac{d \lambda_{d r}}{d t} \\
& 0=R_{r} i_{q r}+\omega_{r} \lambda_{d r}+\frac{d \lambda_{q r}}{d t}
\end{aligned}
$$

The motor electric torque can be given by:

The dynamic equation of the torque is given by:

$$
T_{e}=\frac{3}{2}\left(\frac{P}{2}\right)\left(\lambda_{d s} i_{q s}-\lambda_{q s} i_{d s}\right)
$$

$$
T_{e}=T_{L}+J \frac{d \omega_{m}}{d t}=T_{L}+\frac{2}{P} J \frac{d \omega_{r}}{d t}
$$

From the equations (2) - (11) the IM motor d-q model can be establish, and simulated by using Matlab Simulink software package. The suggested motor is characterized by the parameters shown in table-1.

Table 1. Specifications of the induction motor.

\begin{tabular}{|l|l|}
\hline Nominal Power & $2238 \mathrm{VA}$ \\
\hline Voltage (line to line) & $460 \mathrm{~V}$ \\
Frequency & $60 \mathrm{~Hz}$ \\
Stator resistance and inductance & $0.435 \Omega, 2 \mathrm{e}-3 \mathrm{H}$ \\
Rotor resistance and inductance & $0.816 \Omega, 2 \mathrm{e}-3 \mathrm{H}$ \\
Mutual Inductance & $69.31 \mathrm{e}-3 \mathrm{H}$ \\
Inertia J, pole pairs & $0.089 \mathrm{~kg} \cdot \mathrm{m}^{2}, 2$
\end{tabular}

The drive circuit in this paper built by using space vector voltage source inverter, the simulation of the motor model and the SVPWM VSI are shown in figure.1 below:

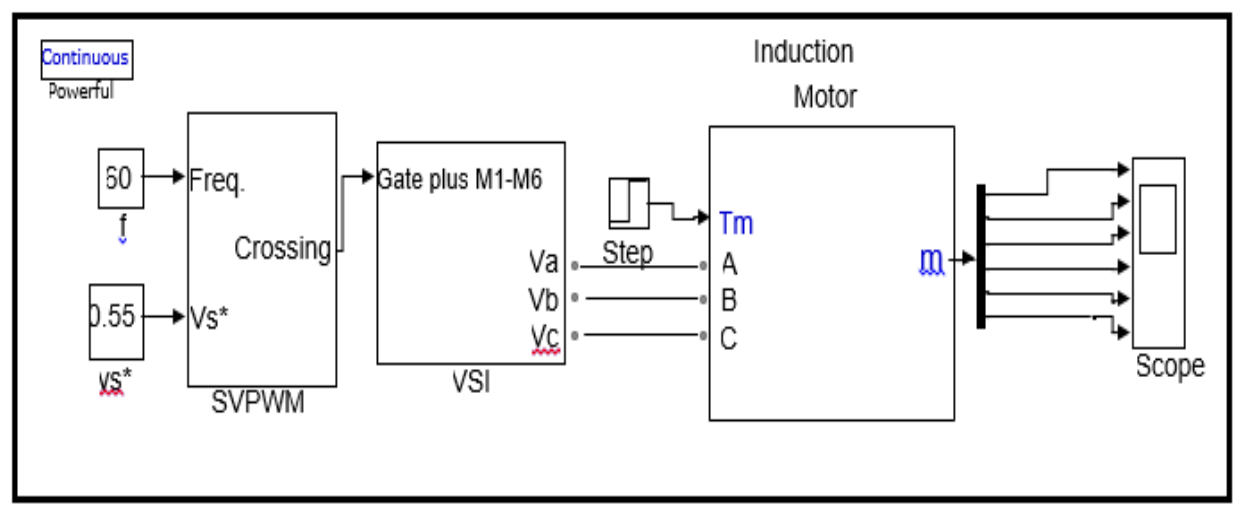

Figure 1. Matlab simulation of the drive circuit and the motor.

The motor speed and torque responses and stator current with sudden load apply of $5 \mathrm{Nm}$ at time instant $3 \mathrm{sec}$ with operating frequency $=60 \mathrm{~Hz}$ are shown in figres(2-4) below: 


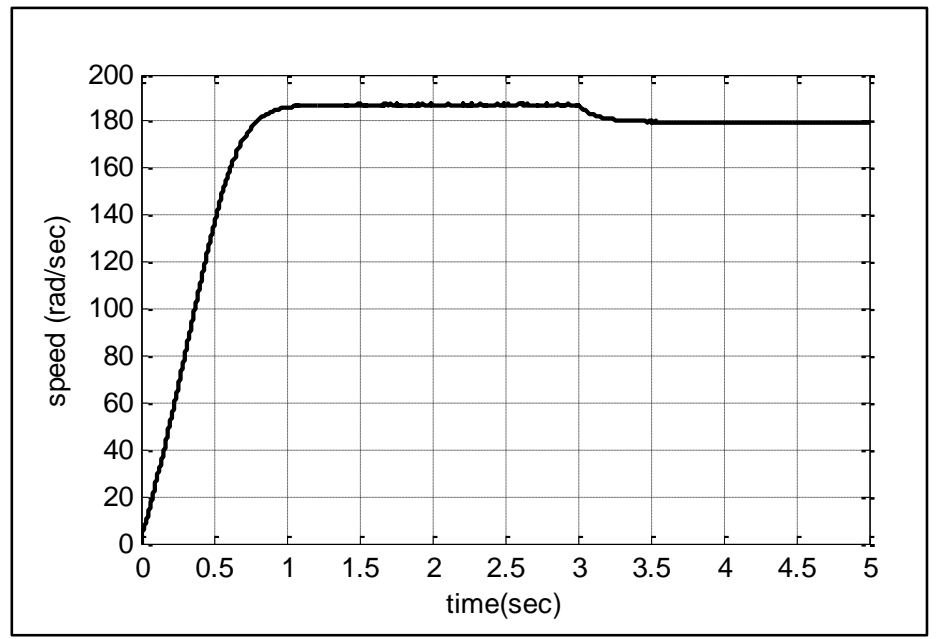

Figure 2. Motor speed response with sudden load of $5 \mathrm{Nm}$ at time $3 \mathrm{sec}$.

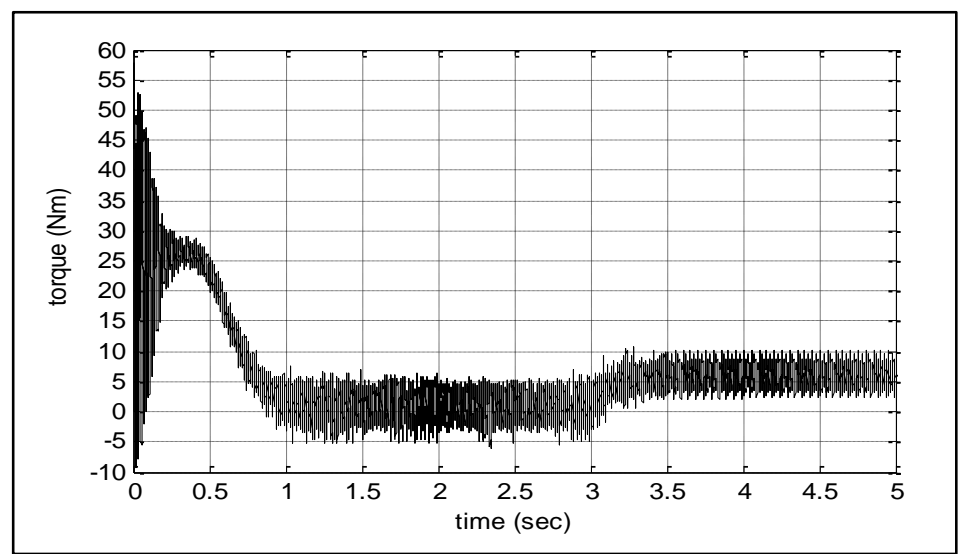

Figure 3. Motor torque response with sudden load of $5 \mathrm{Nm}$ at time $3 \mathrm{sec}$.

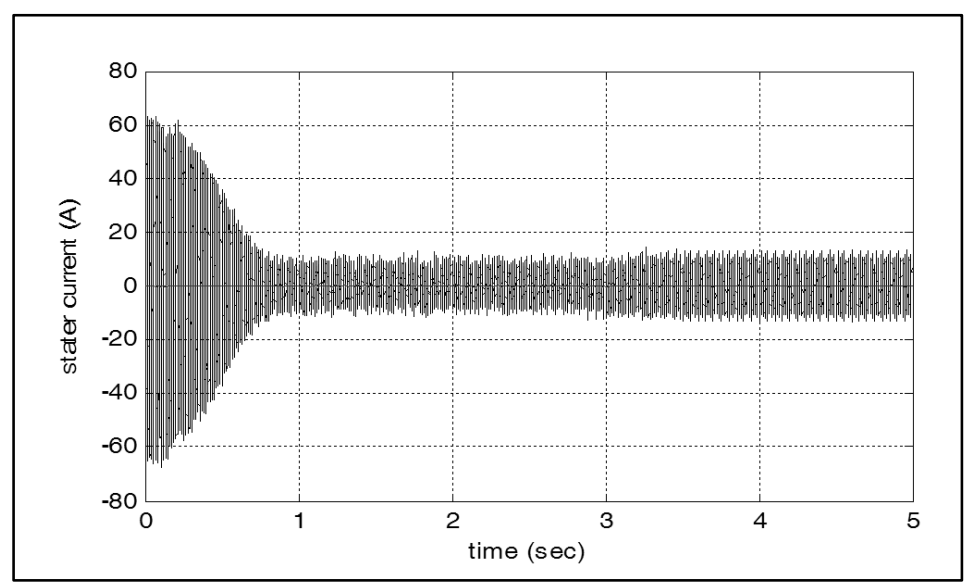

Figure 4. Motor stator current with sudden load of $5 \mathrm{Nm}$ at time $3 \mathrm{sec}$.

The result show that the motor speed profiles is drop from the no-load speed at sudden load changes.

\section{Design of PI controller:}

One of the common IM speed control is based on the PI controller [7-9]. In this paper, the first step start with using traditional PI Controller in the feedback loop. The PI controller input is the speed error signal and can be calculated from difference between the motor speed and the reference speed. The output of the PI controller is feed as frequency and reference magnitude to the space vector inputs, thus the V/F is kept always 
constant under this controller. The Matlab simulation of the PI controller for the IM is shown in figure (5) below:

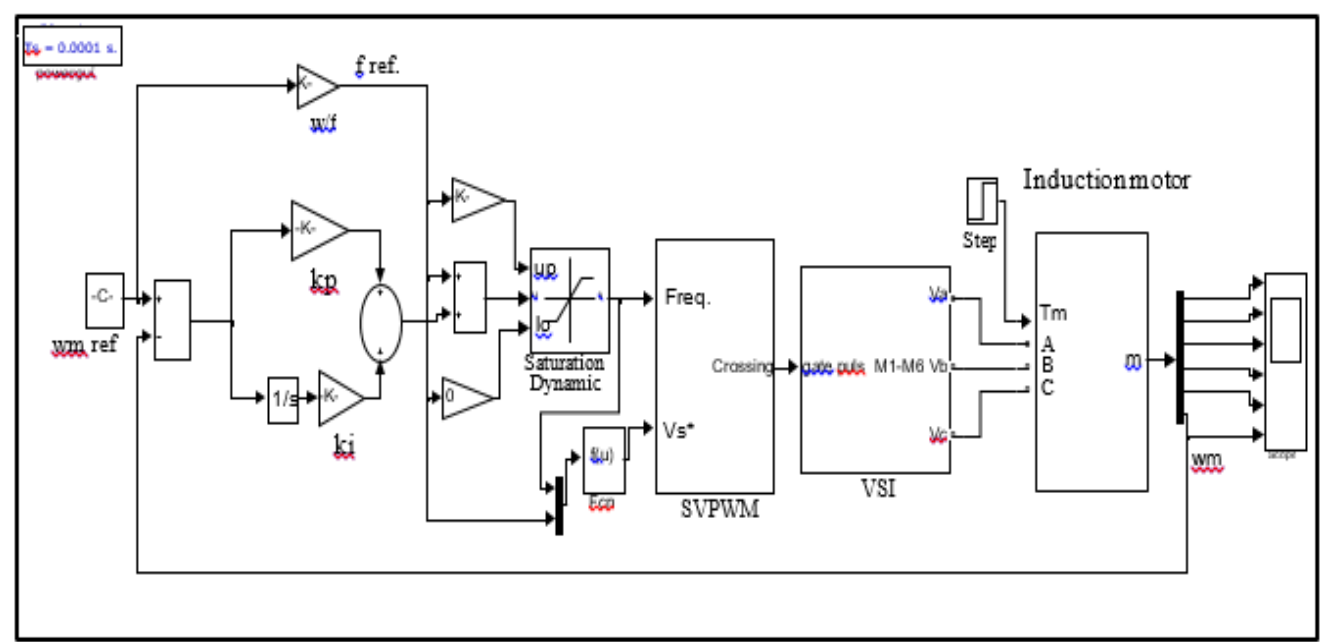

Figure 5. Matlab simulation of the PI controller for the IM.

The simulation result of the motor speed and torque responses with load condition ( $\mathrm{TL}=5 \mathrm{Nm}$ at $\mathrm{t}=3 \mathrm{sec}$, operating frequency $=60 \mathrm{~Hz}$ ) are shown in figures $(6,7)$ :

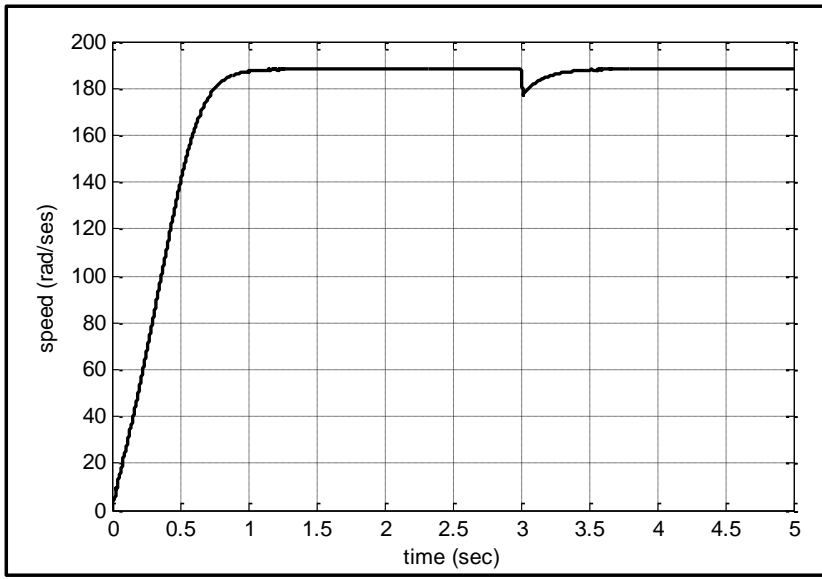

Figure 6. Motor speed response with PI controller with sudden load $\mathrm{T}_{\mathrm{L}}=5 \mathrm{Nm}$ at $\mathrm{t}=3 \mathrm{sec}$.

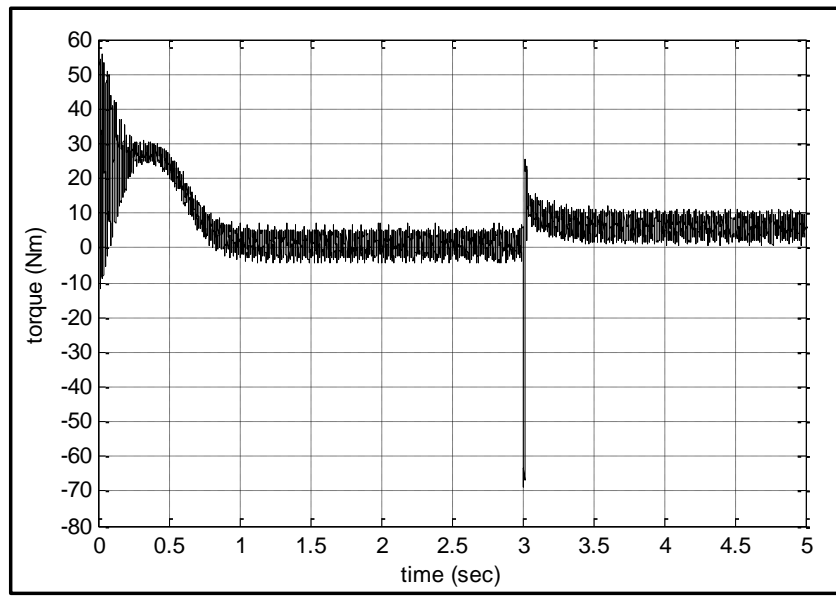

Figure 7. Motor torque response with PI controller with sudden load $\mathrm{TL}=5 \mathrm{Nm}$ at $\mathrm{t}=3 \mathrm{sec}$. 
Figure (6) and (7) show the motor speed and torque profiles under the PI controller with sudden load condition, the speed profile shows the ability of the PI controller to return the motor speed to its reference value, but this controller cannot still work efficiently under different operating point, as shown in motor speed response with operating frequency 80 and $40 \mathrm{~Hz}$ in figures (8) and (9).

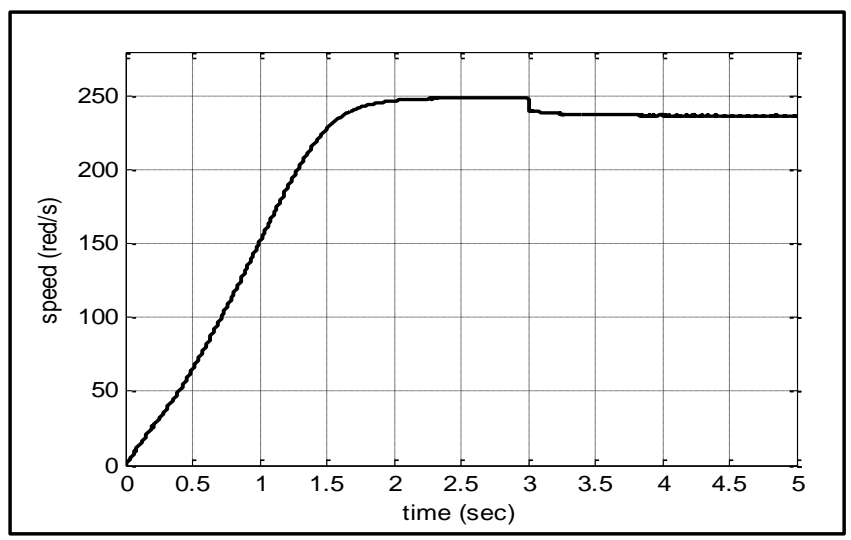

Figure 8. Motor speed response with PI controller $(\mathrm{f}=80 \mathrm{~Hz})$ with sudden load $\mathrm{TL}=5 \mathrm{Nm}$ at $\mathrm{t}=3 \mathrm{sec}$.

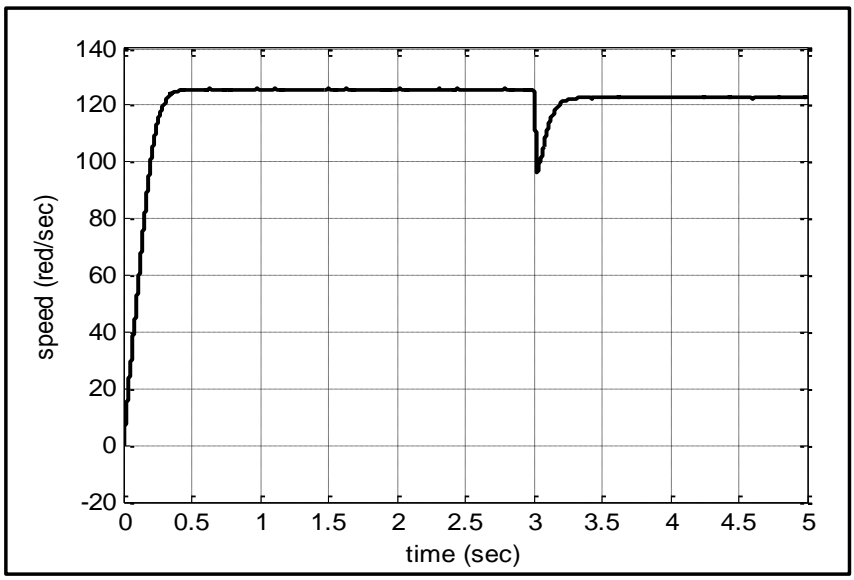

Figure 9. Motor speed response with PI controller $(\mathrm{f}=40 \mathrm{~Hz})$ with sudden load $\mathrm{TL}=5 \mathrm{Nm}$ at $\mathrm{t}=3 \mathrm{sec}$.

\section{Design and simulation of combined PI controller with neural network:}

In this paper a neural network added to the PI controller to develop and enhance the proposed speed controller. The neural network is build with matlab simulation depended on the data of table- 2 . This table contanets the neural input which is the speed error and the neural output is the frequency as given below:

Table 2. The neural network building data.

\begin{tabular}{lllllllllllll}
\hline Neural input & -223 & -200 & -180 & -160 & -140 & -120 & -100 & -80 & -60 & -40 & -20 & 0 \\
Neural output & 40 & 42 & 44 & 46 & 48 & 50 & 52 & 54 & 56 & 58 & 59 & 60 \\
Neural input & 20 & 40 & 60 & 80 & 100 & 120 & 140 & 160 & 180 & 200 & 220 & 223 \\
Neural output & 62 & 64 & 66 & 68 & 70 & 72 & 74 & 76 & 78 & 80 & 82 & 84
\end{tabular}

The matlab simulation of PI controller with neural network is shown in figure (10) below: 


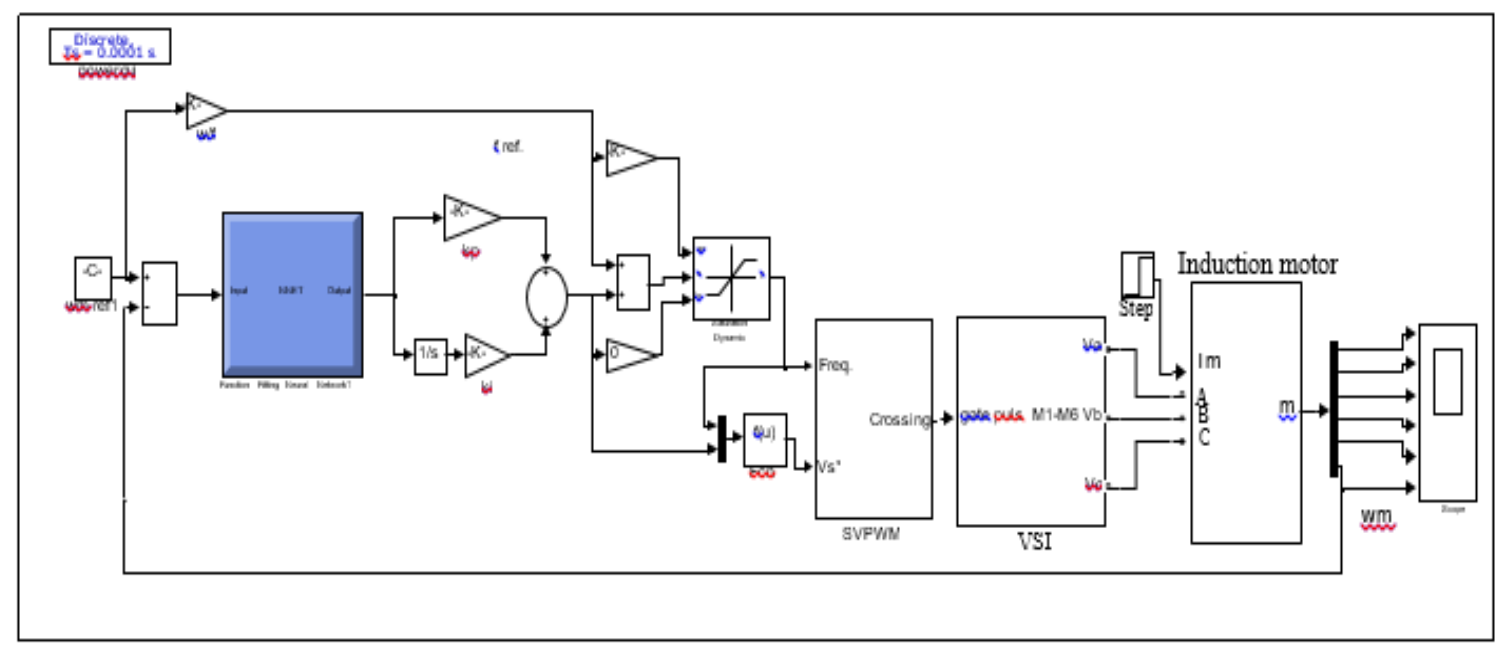

Figure 10. Matlab simulation of PI controller with neural network.

The simulation results of motor speed and torque under sudden load change are shown in figures (11) and (12) with operating frquency $(\mathrm{f}=60 \mathrm{~Hz})$, the reslut show that the motor speed and torque responces are greatly enhanced when the neural network is added to the PI controller. Also the propsed controller is stils work excellently when change the operating frequency as shown in figures (13) and (14) which repersent the motor speed response profiles when the operating frequency 80 and $40 \mathrm{~Hz}$ respectively.

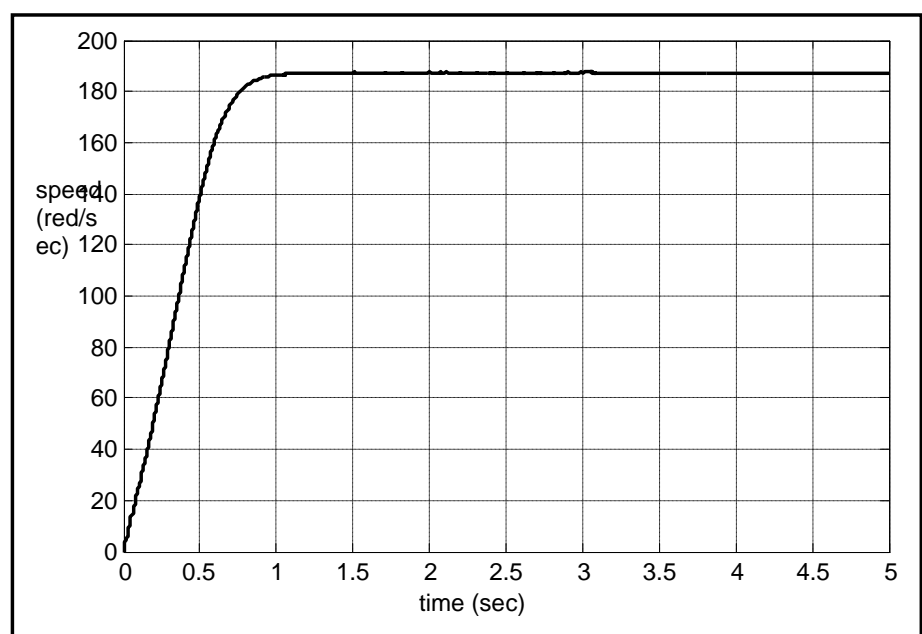

Figure 11. Motor speed response with neural network and PI controller with sudden load $\mathrm{TL}=5 \mathrm{Nm}$ at $\mathrm{t}=3$ $\mathrm{sec}, \mathrm{f}=60 \mathrm{~Hz}$.

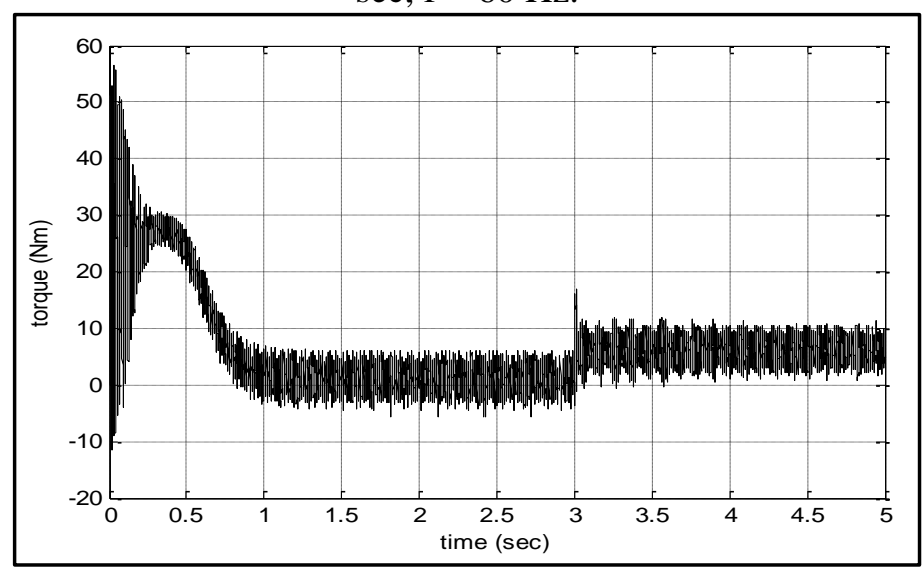

Figure 12. Motor torque response with neural network and PI controller with sudden load $\mathrm{TL}=5 \mathrm{Nm}$ at $\mathrm{t}=3$ sec, $\mathrm{f}=60 \mathrm{~Hz}$. 


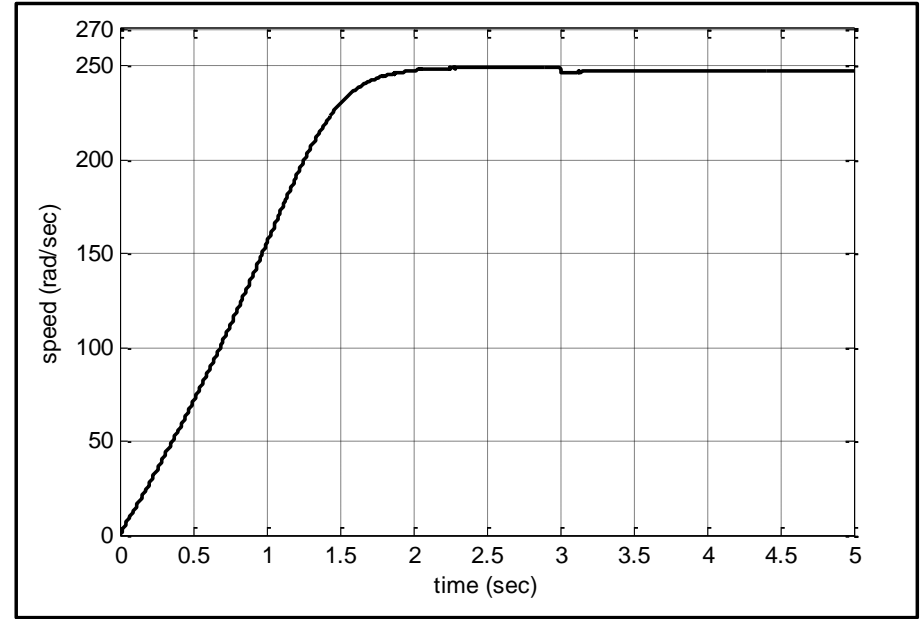

Figure 13. Motor speed response with neural network and PI controller with sudden load $\mathrm{TL}=5 \mathrm{Nm}$ at $\mathrm{t}=3$ sec, $\mathrm{f}=80 \mathrm{~Hz}$.

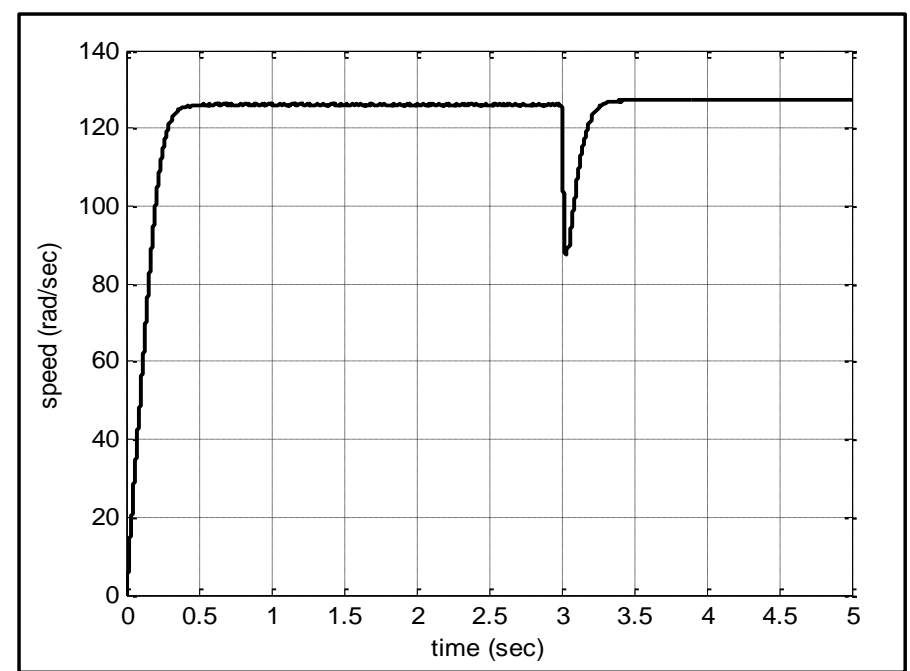

Figure 14. Motor speed response with neural network and PI controller with sudden load $\mathrm{TL}=5 \mathrm{Nm}$ at $\mathrm{t}=3$ sec, $\mathrm{f}=40 \mathrm{~Hz}$.

\section{Conclusions}

In this paper Matlab simulation of combining PI controller with neural network for speed control of IM are presented. The suggested controller has less number of control sensors. The motor speed and torque profiles under the propose controller are compared with the traditional PI controller and the results show the following:

1. The motor speed and torque profiles are greatly improved under sudden load applied and the speed transient behavior and oscillation are extremely eliminated under the load condition.

2. The proposed controller still work efficiently when the operating frequency varied up and down the rated operating frequency, better than the traditional PI controller.

\section{References}

[1] F. Zidani, M.S. Nait Said, D. Diallo, 'Fuzzy Optimal Volts/Hertz Control Method for an Induction Motor', IEMDC 2001. IEEE International Electric Machines and Drives Conference (Cat. No.01EX485), pp.377-381. 
[2] Jugraj M., Kanhaiya L. G., Keshavchand M., Keshav N. M., Omprakash B., ' Speed Control of Induction Motor by using Closed Loop Inverter Circuit' International Journal for Research in Technological Studies, Vol. 4, Issue 4, March 2017, pp.23-26.

[3] Devraj J., Nikhar P., ' V/f CONTROL OF INDUCTION MOTOR DRIVE', Thesis, Department of Electrical Engineering National Institute of Technology Rourkela, ODISHA, INDIA-769008, p.23-35.

[4] Sifat S., A. Rashid, MKL Bhatti, ' Direct Quadrate (D-Q) Modeling of 3-Phase Induction Motor Using MatLab / Simulink' Canadian Journal on Electrical and Electronics Engineering Vol. 3, No. 5, May 2012, pp.237-243.

[5] Dr. Omar Albarbarawi, Dr. Ayman Y. Al-Rawashdeh, Dr. Ghazi Qaryouti, ' Simulink Modelling of the Transient Cases of Three Phase Induction Motors', International Journal of Electrical \& Computer Sciences IJECS-IJENS Vol:17 No:04, pp.6-15.

[6] Naintara Wasnik, Prof. M. V. Palandurkar, ' Simulation Of Induction Motor Modelling In MATLAB Software' International Journal of Engineering Research \& Technology (IJERT), ISSN: 2278-0181, Vol. 2 Issue 4, April 2013, p.p. 2254- 2258.

[7] Farzad Razavi, Beitollah Ghadiri, 'Imperialist Competitive Algorithm (ICA)-Optimized PI Speed Control in the Indirect Field-Oriented Control of an IM Drive' IEEE Colloquium on Humanities, Science and Engineering Research, INSPEC Accession Number: 12577514, 2011, p.p.445 - 448.

[8] Yugal Kishor Sahu, Kahkashan Quraishi, Soma rajwade, 'Comparative Analysis of PI \& Fuzzy Logic Controller Based Induction Motor Drive', International Conference on Electrical Power and Energy Systems(ICEPES), INSPEC Accession Number: 16854511, 2016, p.p. 210-214.

[9] Sushma J Patil, M S Aspalli, 'Study of AI and PI Controller using SVPWMTechnique for Induction Motor Speed Control', International Conference on Electrical, Electronics, Communication, Computer and Optimization Techniques (ICEECCOT), INSPEC Accession Number: 17576714, 2017, p.p.676-681. 